Special issue of the 2nd International Conference on Computational and Experimental Science and Engineering (ICCESEN 2015)

\title{
Variation over Time of the Perez Calibration Algorithm for Ground-Based Spectrometer
}

\author{
Su Na Chin, N.V. Boyou, R.B. Yusoff, Ag. Sufiyan Abd. Hamid, F. Sulaiman \\ AND J. DAYOU* \\ Energy, Vibration and Sound Research Group (e-VIBS), Faculty of Science and Natural Resources, \\ Universiti Malaysia Sabah, Jalan UMS, 88400 Kota Kinabalu, Sabah, Malaysia
}

\begin{abstract}
A spectrometer is likely to perform as expected over a period of time if calibrated with suitable method. This paper aims to study the variation of the Perez calibration algorithm over time for a spectrometer. The study was carried out for six months from July to August 2012 and January-April 2013. The measurements were recorded for every minute interval from 8.30 a.m. to 4.30 p.m. in three locations in Kota Kinabalu, Sabah, Malaysia. Monthly calibration constants for eight wavelengths were determined for the Perez model using improved Langley method. When only wavelengths which are close to $500 \mathrm{~nm}(460,500,540,580$, and $620 \mathrm{~nm})$ were engaged, the variations over time of the Perez calibration constants were consistent over time $(F=1.381, p=0.273)$. This is similar to the previous finding on the Du Mortier algorithm.
\end{abstract}

DOI: 10.12693/APhysPolA.130.160

PACS/topics: 92.60.Sz, 96.60.Ub

\section{Introduction}

TABLE I

Aerosol optical depth (AOD) represents the total attenuation of solar terrestrial radiation caused by aerosol. Its measurement was often performed using ground-based spectrometer because of its accuracy, and high spectral and temporal resolution [1]. However, a spectrometer must be calibrated to read in physical units $\left(\mathrm{W} / \mathrm{m}^{2} / \mathrm{nm}\right)$. A spectrometer is likely to perform as expected over a reasonable period of time, if it is calibrated with suitable method. Chang et al. [1] developed a new Langley calibration algorithm which combined the Perez-Du Mortier model to allow frequent calibration. When taking into account of the Du Mortier sky condition alone, the calibration constant obtained were consistent and was valid over time [2]. This study was carried out to evaluate the consistency of the calibration algorithm for AOD measurement using the Perez sky clearness index.

\section{Methodology}

\subsection{Sky classification using the Perez model}

The Perez model is one of the most acknowledged models. It is often used for predicting the daylighting in building design [3]. The Perez sky clearness index for irradiance is given by [4]:

$$
\varepsilon=\frac{\frac{\underline{I e d}_{\text {ed }}+I_{\mathrm{dir}}}{I_{\mathrm{ed}}}+1.041 \theta_{\mathrm{H}}}{1+1.041 \theta_{\mathrm{H}}} .
$$

$I_{\text {ed }}$ and $I_{\mathrm{dir}}$ are diffused and direct irradiance $\left(\mathrm{W} / \mathrm{m}^{2}\right)$ and $\theta_{\mathrm{H}}$ is the zenith angle (rad). The classification of sky conditions by Perez is represented in Table I.

\footnotetext{
* corresponding author; e-mail: jed@ums .edu.my
}

Perez et al. classification of sky conditions.

\begin{tabular}{c|c|c|c}
\hline $\begin{array}{c}\text { Clearness index } \\
(\varepsilon)\end{array}$ & $\varepsilon \geq 4.5$ & $1.23<\varepsilon<4.5$ & $\varepsilon \leq 1.23$ \\
\hline sky condition & clear sky & $\begin{array}{c}\text { partly cloudy } \\
\text { or intermediate }\end{array}$ & $\begin{array}{c}\text { cloudy } \\
\text { or overcast }\end{array}$
\end{tabular}

\subsection{Improved Langley method}

The improved Langley method [5] which depends on a known calibration for a reference wavelength permits calibration at the others by assuming the relative size distribution of aerosol to remain constant as Eq. (2), so that the ratio of aerosol optical depth between different wavelengths are assure to be constant as Eq. (3):

$$
\begin{aligned}
& \tau_{\mathrm{a}}(\lambda, t)=\pi A(t) \int K_{\text {ext }}(r, \lambda) f(r) \mathrm{d} \ln r, \\
& \frac{\tau_{\mathrm{a}}\left(\lambda_{1}, t\right)}{\tau_{\mathrm{a}}\left(\lambda_{2}, t\right)}=\frac{\tau_{\mathrm{a}}\left(\lambda_{1}, t_{0}\right)}{\tau_{\mathrm{a}}\left(\lambda_{2}, t_{0}\right)}=\Psi .
\end{aligned}
$$

$\tau_{\mathrm{a}}$ - optical depth of aerosol, $f(r)$ - relative size distribution that is dependent only on particle radius $r$, $A(t)$ - multiplier necessary to produce the correct size distribution at time $t$ and $\Psi$ is constant. The calibrations at the other wavelengths can be performed by using

$$
\begin{aligned}
& \ln F\left(\lambda_{1}\right)+m\left[\tau_{m}\left(\lambda_{1}\right)+\tau_{0}\left(\lambda_{1}\right)\right]= \\
& \quad \ln F_{0}\left(\lambda_{1}\right)-\Psi m \tau_{\mathrm{a}}\left(\lambda_{0}\right),
\end{aligned}
$$

where $\lambda_{0}, \lambda_{1}$ are the reference and calibrated wavelength, $m$ is approximate air mass.

\subsection{Experimental methodology}

Data collected using a spectrometer (Fig. 1) were filtered according to the Perez model to determine the sky conditions and to identify the highest clearness index. The study was conducted at 3 locations 
in Kota Kinabalu: Science and Technology Complex (Universiti Malaysia Sabah) (6 ${ }^{\circ}$ 'N, $\left.116^{\circ} 7^{\prime} \mathrm{E}\right)$, Damai $\left(5^{\circ} 58^{\prime} \mathrm{N}, 116^{\circ} 5^{\prime} \mathrm{E}\right)$ and Queen Elizabeth Hospital $\left(5^{\circ} 55^{\prime} \mathrm{N}, 116^{\circ} 2^{\prime} \mathrm{E}\right)$. The locations of study are of great importance due to the coordinates of each location that was used in the calculation of the clearness index.

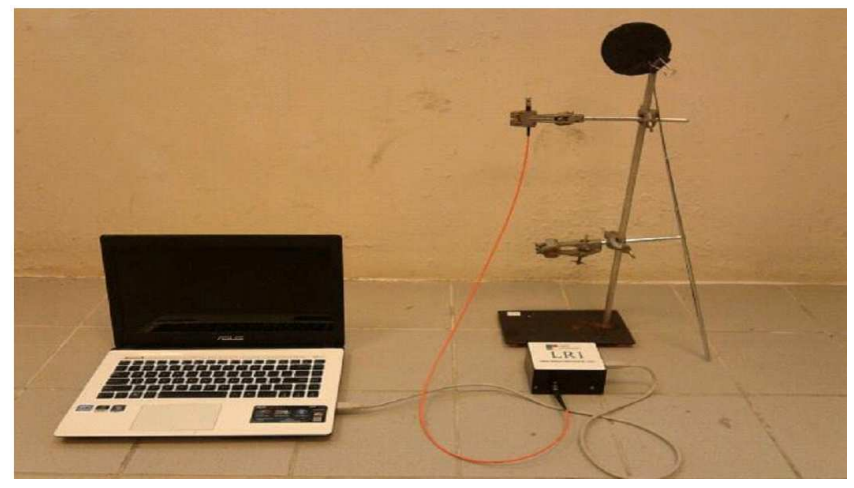

Fig. 1. Spectrometer setup.

A higher ground level was chosen so that the solar pathway was not blocked by irrelevant objects. The intensity of the sunlight was measured every minute interval from 8.30 a.m. to 4.30 p.m., in July-August, 2012, as well from January to April 2013. First data was collected as "Global", (direct sun sunlight), followed by "Diffused" (diffused radiation from the sun measured using diffuser).

The monthly calibration constant for 8 wavelengths was calculated using the formulae from (2) to (4). Then, the highest sky classifications of the Perez model were identified and were compared using analysis of variance (ANOVA).

\section{Result and discussion}

From Fig. 2, all the selected months show $0 \%$ frequency occurrences for clear sky condition. This means majority of the sky condition in July and August were partly cloudy or intermediate. For the rest of the months, majority of the sky conditions were classified as cloudy or overcast. Therefore, a decision was made where the data consisting of the highest clearness index are taken into consideration for developing the calibration constant.

ANOVA result showed a statistical significant mean difference in calibration constants across months $(F=$ $\left.6.585, p=2.048 \times 10^{-4}<0.001\right)$. A Tukey post hoc test revealed statistically significant differences between mean calibration constants in August and January $(p=0.031)$, August and February $(p=0.009)$, January and April $(p=0.003)$, February and April $(p=0.001)$.

Scatter plot in Fig. 3 suggests that the majority of the differences were contributed by variation in calibration constant of wavelength 420, 660, and $700 \mathrm{~nm}$ across months. By taking out these wavelengths, we performed another ANOVA test on the remaining data $(460,500,540,580$, and $620 \mathrm{~nm})$. The finding shows

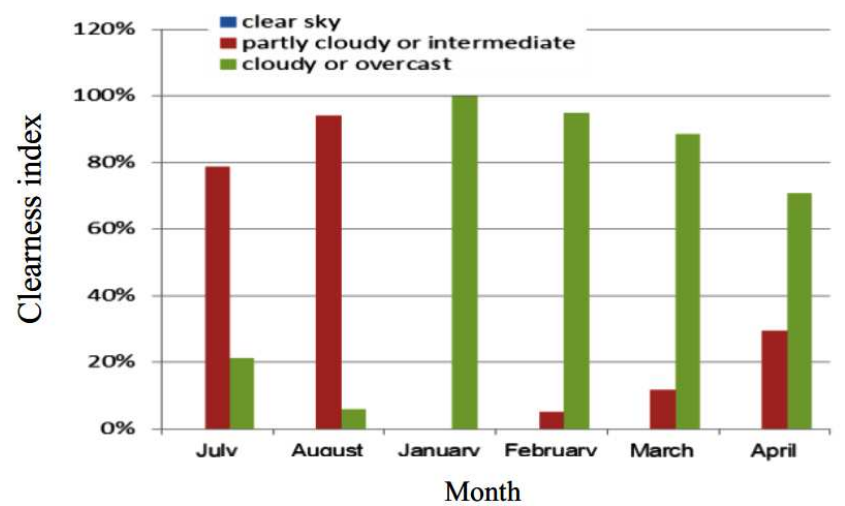

Fig. 2. Clearness indices $(\varepsilon)$ classifications using the Perez model.

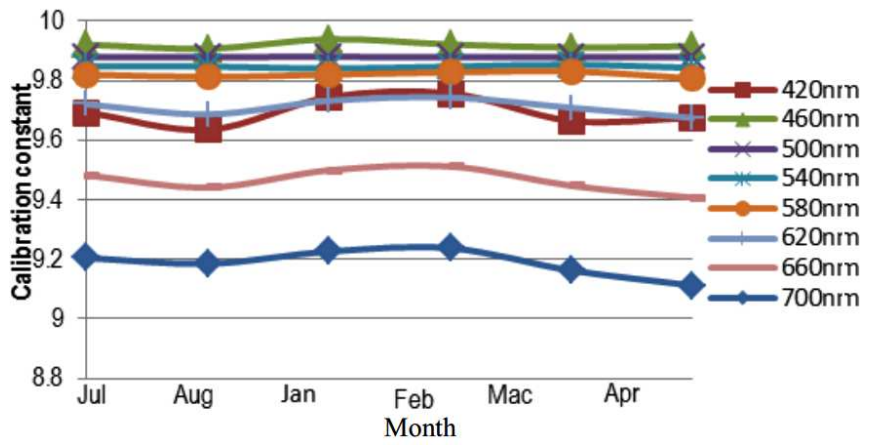

Fig. 3. Variations in calibration constant using improved Langley method with Perez sky clearness index.

no statistically significant mean difference in calibration constant across months $(F=2.275, p=0.086>0.05)$.

\section{Discussion and conclusion}

The calibration constants considered equal across months for wavelengths $=460,500,540,580$, and $620 \mathrm{~nm}$. When the results were compared with the Du Mortier model [2], both shows consistency overtime for the same wavelengths. This is because these wavelengths are close to the $500 \mathrm{~nm}$ wavelength which is the most stable wavelength in the visible range [6]. Therefore, overall, the Perez calibration algorithm is valid over time. Weaker irradiance decreases the spectrometer sensitivity at other wavelengths contribution to the deviations in these wavelengths [7].

\section{Acknowledgments}

This research was supported by the Malaysian Ministry of Education under the research grant number RAG0021STWN-2012, and is greatly acknowledged.

\section{References}

[1] J.H.W. Chang, J. Dayou, J. Sentian, Aerosol Air Qual. Res. 14, 386 (2014). 
[2] R. Yusoff, N.V. Boyou, J. Dayou, S.N. Chin, A.S.A. Hamid, F. Sulaiman, N.H.N. Maizan, Adv. Environm. Biol. 9, 14 (2015).

[3] H. Djamila, C.C. Ming, S. Kumaresan, Renew. Energy 36, 9 (2010).

[4] R. Perez, P. Ineichen, R. Seals, J. Michalsky, R. Stewart, Solar Energy 44, 271 (1990).
[5] K. Arai, X.M. Liang, Int. J. Appl. Sci. 2, 93 (2011).

[6] J.H.W. Chang, J. Dayou, J. Sentian, World Acad. Sci. Eng. Technol. 73, 1112 (2013).

[7] P. Weihs, I. Dirmhirn, I.M. Czerwenka-Wenkstetten, Theor. Appl. Climatol. 51, 97 (1995). 